\section{IMBRICAÇÕES FOTONARRATIVAS \\ NO FILME ACOSSADO (À BOUT DE \\ SOUFFLE), DE JEAN-LUC GODARD}

\author{
Andressa Liz Menezes Ferro \\ Graduanda em Teoria, Crítica e História da \\ Arte \\ Universidade de Brasília
}

\title{
Resumo
}

Esse artigo tem como eixo temático o diálogo entre visualidade e textualidade a partir da análise do filme Acossado, de Jean-Luc Godard. Esse filme foi um dos pioneiros da "Nouvelle Vague", movimento cinematográfico da década de 60 que instaurou uma nova linguagem do cinema. Essa nova linguagem nasce a partir da proposta de um cinema autoral e inovações de técnicas narrativas que proporcionam uma diversidade de interpretações e diálogos que se dão pela quebra da narrativa tradicional cinematográfica. O filme de Godard apresenta um contínuo interstício entre imagens que dialogam diretamente com o espectador fazendo com que sua ação de ver o filme se torne ativa, e não passiva.

Palavras-chave: Nouvelle

Vague; Godard; Acossado; Cinema ; Se miótica.

\section{Abstract}

This article proposes a dialogue between visuality and textuality based on the analysis of Jean-Luc Godard's film À Bout de Souffle. This film was one of the pioneers of "Nouvelle Vague", a movement

of the 60 s that introduced a new language of cinema. This new language is born from the proposal of an author's cinema and innovations of narrative techniques that provide a diversity of interpretations and dialogues that are given by the breaking of the traditional cinematographic narrative structure. Godard's film presents a continuous interstice between images that dialogue directly with the viewer making the action of watching a movie become active rather than passive.

Key-words: Nouvelle Vague; Godard; À Bout de Souffle; Cinema; Semiotics.

A Nouvelle Vague surge a princípio como um slogan jornalístico de uma pesquisa sociológica através de vários artigos que foram publicados inicialmente para a revista L'Express (L'Express, n. 71, maio de 1957), popularizados pela jornalista Françoise Giroud. Essa pesquisa tem como cerne os fenômenos de gerações dado o surgimento na França de uma cultura jovem do pós-guerra que estava muito próxima com a cultura americana. A popularização da "nova onda" assimilou questões sociais referentes a novos hábitos da cultura jovem e moderna, como a emancipação das mulheres, novos hábitos morais e modo de vida posteriormente retomados por vários pesquisadores.

Portanto, podemos dizer que a Nouvelle Vague não foi uma expressão utilizada primeiramente no cinema. Contudo, essa mudança geracional 
influenciaria toda a cultura francesa e consequentemente o cinema. Alguns anos após essas publicações, jornalistas e críticos cinematográficos propuseram uma pesquisa sobre o cinema francês que seria afetado por essa onda jovem crescente na França. Como exemplo, o jornalista e crítico Pierre Billard anunciou uma divisão entre os diretores de cinemas influentes na época, marcada pelos antigos e os novos de acordo com suas datas de nascimento respectivas. Posteriormente, revistas como a L'Express (L'Express, n. 71, maio de 1957) passam a atribuir a expressão "Nouvelle Vague" ao cinema de modo a identificar e antever um novo cinema que se esboçava na França.

É mais uma vez L'Express que retoma a expressão Nouvelle Vague para atribuí-la aos novos filmes distribuídos no início de 1959 e, mais particularmente às novas obras exibidas no Festival de Cannes do mesmo ano. Dessa Vez, a origem geracional e social do termo é logo descartada em prol de sua aplicação mais estritamente cinematográfica. (MARIE, 2011, p. 15).

Esse novo cinema fundamentado por teóricos e críticos da revista Cahiers $d u$ Cinema criou divisões muito mais complexas entre o cinema novo e o velho do que apenas a data de nascimento de cada diretor.

A Nouvelle Vague teve seu início na história do cinema em 1959. Desde pouco antes de seu estabelecimento como movimento cinematográfico, críticos como Pierre Billard escreviam sobre a esclerose do cinema clássico francês, definindo-o como um cinema pouco inovador e de prosperidade econômica.

Billard salienta que a inegável prosperidade econômica do cinema francês no período é acompanhada de uma profunda crise artística: 'O esgotamento da inspiração, a esterilidade dos temas e o imobilismo estéticos são dificilmente contestáveis: com raras exceções, os melhores filmes desses últimos anos pertencem, quanto a sua forma e seu conteúdo, a concepções caducas. (MARIE, 2011, p. 21).

Essa questão levantada por Billard fora retomada por vários críticos que impulsionaram o movimento, dentre eles François Truffaut e Jean-Luc Godard. Essa questão se tornou um dos principais motivos para a revolução estética no novo cinema francês.

Esses jovens críticos e cineastas que impulsionaram a Nouvelle Vague partem de um dedicado e profundo estudo da historiografia do cinema e um constante desejo de inovação baseados nos novos costumes de suas gerações, tornando assim o movimento coerente, independentemente de seu curto prazo de duração.

Um grande texto que serviu como base para o nascimento da Nouvelle Vague foi o manifesto de Alexandre Astruc, intitulado "Naissance d'une nouvelle 
avant-garde: La caméra stylo"

(Nascimento de uma nova vanguarda: A câmera caneta) publicado em L'Écran Français (L'Écran Français, n. 144, março de 1948). Esse texto propôs o cinema como meio de expressão do artista, tanto quanto qualquer outra forma do fazer artístico como pintura ou literatura, denunciando a sequela do cinema espetáculo que buscava traduzir grandes obras literárias para o cinema ao invés de propor um modo de fazer cinematográfico criativo e crítico que dialogasse com as obras literárias, em vez de apenas tentar adaptá-las.

"Depois de ter sido, sucessivamente, uma atração de feira, um divertimento análogo ao teatro de boulevard, ou um meio de conservar as imagens da época, ele se torna uma linguagem. Uma linguagem, ou seja, uma forma na qual e pela qual um artista pode expressar seu pensamento, por mais abstrato que seja, ou traduzir suas obsessões, exatamente como acontece hoje com o ensaio ou o romance. Por isso chamo essa nova idade do cinema de 'camérastylo'.” (MARIE, 2011, p. 33).

Esse conceito chave que inauguraria a Nouvelle Vague como "cinema de autor", anteriormente proposto por Truffaut, colocaria o diretor como único criador e autor da obra cinematográfica em detrimento do processo coletivo na criação do filme, de modo a atacar todos os influentes diretores do cinema clássico francês (considerado cinema de qualidade) que buscavam adaptações de obras literárias. Segundo Michel Marie, a mise-en-scène (direção) adquiriu uma importância ainda maior quando passou a ser definida como $o$ olhar do autor (MARIE, 2011, p. 42).

$\mathrm{O}$ argumento de Truffaut contra as adaptações consistia em afirmar que os diretores do cinema de qualidade se tornavam meros funcionários dos roteiristas, vítimas da ditadura da dramaturgia verificando aí uma atitude protocolar e subserviente diante do potencial do estilo. Para a geração da Nouvelle Vague, é a mise-en-scène a grande expressão, o espaço da autenticidade, o espaço dos autores. (MASCARELLO, 2012, p. 236).

Outra característica que marcou a Nouvelle Vague foi o baixo orçamento dos filmes produzidos, que visava romper totalmente com o modo das produções hollywoodianas. Os filmes desse movimento eram feitos em uma espécie de cooperativa de produção entre diretores/autores, críticos e colegas de produção, de modo que pudessem produzir seus filmes com o menor orçamento possível e ajudar conjuntamente na divulgação e promoção do filme. Muitos diretores trabalharam em conjunto na construção dos filmes durante o movimento, como Truffaut, Godard e Chabrol. Essa recusa por grandes orçamentos em um momento de prosperidade econômica no cinema francês 
exemplificava mais uma ruptura conceitual do movimento da Nouvelle Vague com o cinema clássico e os moldes hollywoodianos de superproduções. O interesse desses novos diretores passava por uma revolução e renovação da estética e produção cinematográfica para a criação de filmes críticos ao invés de grandes clássicos do cinema de espetáculo. Tais renovações podem ser exemplificadas como: (i) a preferência por cenários naturais, sem alterações pré-estabelecidas e até mesmo sem o auxílio de iluminação adicional, (ii) o grande espaço destinado a improvisação de atores ao invés da direção contínua e frequente que o diretor clássico exerce sobre seus atores, (iii) a utilização de uma equipe com poucas pessoas e o grande trabalho exigido na montagem do filme. "Essas escolhas visam eliminar as fronteiras entre cinema profissional e amadorismo, assim como entre filme de ficção e filme documentário ou filme de pesquisa.” (MARIE, 2011, p. 66).

Jean Luc-Godard foi um dos percussores desse movimento e, com seu primeiro longa-metragem Á Bout de Souffle (Acossado), tornou-se um cineasta de grande importância para o lançamento da Nouvelle Vague. Antes de dirigir seu primeiro longa, foi crítico cinematográfico na revista Cahiers du Cinema (revista que mais promovia os filmes produzidos na Nouvelle Vague) e também dirigiu alguns curtas metragens como Tous les garçons s'appellant Patrick (1957) e Charlotte et son Jules (1958). Godard era um grande apreciador do cinema americano e também um grande conhecedor da historiografia do cinema, da literatura e pintura. É notório o uso de referências em seus filmes, frequentemente recortados de diversos campos do conhecimento e das artes para tecer uma densa e complexa cadeia de transtextualidades em seus diálogos.

O filme Acossado será o objeto de análise desse artigo, sendo este o primeiro filme do autor/diretor Jean-Luc-Godard a marcar uma ruptura no cinema clássico e transformar toda a história do cinema posterior. O filme nasce a partir de um roteiro escrito por François Truffaut posteriormente modificado e adaptado por Godard. Acossado levou menos de 4 semanas para ser filmado e foi lançado em 1960. É de grande importância ressaltar os nomes do produtor Georges de Beauregard e do fotógrafo Raoul Coutard, sem os quais o filme não seria o mesmo.

De início a temática escolhida para esse filme se mostra muito diferente do excesso de drama, heroísmo e grandiosidade do cinema clássico. Acossado narra a história de Michel Poiccard, um criminoso inconsequente (interpretado por Jean-Paul Belmondo) que se apaixona por Patricia, uma jovem jornalista americana (interpretada por Jean 
Seberg). Logo no início da trama, Poiccard mata um policial e passa a ser perseguido pela polícia em seu retorno a Paris. Os planos de Michel envolvem encontrar um amigo que lhe dará dinheiro para fugir com Patricia para a Itália. O roteiro escrito por Godard sofreu grande influência do cinema noir americano (cinema de temática policial) apesar de subverte-lo ao longo do filme. Os personagens do filme apresentam características muito diferentes do cinema clássico, ainda que a atuação de Belmondo se assemelhe ao tipo dos atores americanos como Bogart e Jean Gabin, Michel não é nada empático ao público. Mostra-se como um ladrão e grande conhecedor de carros, misógino e orgulhoso demais. Patricia aparece com seu forte sotaque americano, erros de gramática, visual moderno, simples, diferente das demais mulheres da época, com uma certa androgenia. Retratada como uma narcisista, sempre a observar seu reflexo no espelho, uma jovem bem resolvida e com dúvidas a respeito de seus sentimentos por Michel. Outros personagens que aparecem no filme em sua maioria são atores sem experiência em atuação e amigos de Godard como, por exemplo, o personagem Parvulesco (escritor entrevistado no filme por Patricia) que foi interpretado pelo cineasta JeanPierre Melville, um dos inspiradores da Nouvelle Vague. Acossado por mais elementos de trama policial que tenha, acaba se transformando em uma história amorosa com final trágico, em uma trama que retrata morte e desejo. Vários elementos no filme antecedem o fim trágico de Michel Poiccard, que foi morto pela polícia após ser denunciado por Patricia. Nota-se, por exemplo, um cartaz que passa durante o filme no qual está escrito "Viver perigosamente, até o fim" ou mesmo em uma pergunta que faz a Patricia "Você pensa na morte as vezes? Eu sempre penso".

Godard foi um grande inovador da expressão cinematográfica. Junto a Raoul Coutard, os métodos de filmagem foram simplificados de forma a não retardar as filmagens, como a substituição de travellings, grua e tripé, por objetos não convencionais. Nota-se na cena em Champs-Élysées, por exemplo, que o plano-sequência é filmado de modo a não ser percebido pelos transeuntes.

A grua e o tripé também são substituídos por uma cadeira de rodas alugada. $\mathrm{O}$ operador carrega a câmera na mão e, sempre que possível, utiliza a técnica de reportagem televisiva, com a câmera escondida, filmando os atores no meio da multidão anônima. Além da cadeira de rodas, a lenda reteve o uso do triciclo dos correios, empurrado por um assistente, dentro do qual o operador ficava disfarçado. (MARIE, 2011, p. 180).

Essa citação exemplifica o trabalho do fotógrafo na execução do filme, que 
deveria estar preparado para todas as ocasiões e imprevistos, visto que o método não tradicional de filmagem faz com que seu trabalho seja completamente influenciado e demande mais de sua criatividade e olhar do que de aparatos e ideias técnicas.

Acossado é também um retrato de Paris. A arquitetura da cidade, os pontos turísticos, a vida parisiense são evidenciados em várias cenas de filmagens externas como na cena em ChampsÉlysées onde Michel e Patricia andam e conversam. Ao fundo podemos observar toda a paisagem parisiense sem modificações, fazendo com que a cena tenha um valor extra-fílmico, isto é, um valor além da história que estava se desenvolvendo. É pertinente a preferência de Godard por cenários naturais e pela ocupação do cinema na cidade, fazendo com que o filme também seja lembrado como um cartão postal de Paris.

Essas rupturas propostas pelo cinema moderno e por Godard têm como principal característica a importância do todo sobre as partes. No cinema moderno isso se dá, segundo Deleuze, através do interstício entre imagens, criando a definição "o Todo é o fora" (DELEUZE, 1985 , p. 216), ou seja, recorrendo ao que está fora do plano. No filme godardiano, esses interstícios acontecem através da descontinuidade do filme por saltos e falsos raccords ${ }^{1}$. Já o cinema clássico buscava uma harmonia das imagens através da montagem, combinação e continuidade de cenas, como Deleuze definiu, "o Todo era o aberto" (Idem).

O todo não parava de se fazer, no cinema, interiorizando as imagens e se exteriorizando nas imagens, conforme uma dupla atração. Era este um processo de totalização sempre aberta, que definia a montagem e a força do pensamento. Quando se diz "o todo é o de-fora", procede-se de modo bem diferente. Pois, primeiro, a questão não é mais a da associação ou da atração das imagens. O que conta é, ao contrário, o interstício entre imagens, entre duas imagens: um espaçamento que faz com que cada imagem se arranque ao vazio e nele recaia. A força de Godard não está apenas em utilizar esse modo de construção em toda a sua obra (construtivismo), mas em fazer dele um método a respeito do qual o cinema deve se interrogar ao mesmo tempo que o utiliza. (Idem).

Esse novo modo de fazer cinema produz imagens através do pensamento e propõe ao espectador um pensamento crítico através da intersecção das imagens. Essa intersecção de imagens e pensamento é definida por Deleuze como o “entre”, isto é, entre duas imagens, porque para Deleuze: “(...) o todo sofre uma mutação,

\footnotetext{
${ }^{1}$ Do ponto de vista estético, trata-se, antes, de uma mudança de plano que escapa à lógica da transparência que atua na articulação.

(AUMONT, 2003).
} 
pois deixou de ser o Um-ser, para se tornar o "e" constitutivo das coisas, o entre-dois constitutivo das imagens". (Idem, p. 217).

Assim o cinema e o pensamento se unem, não sendo apenas um ou outro, mas sim uma unidade. Os métodos que Godard utiliza para fazer seu filme estão diretamente relacionados a seu pensamento crítico, como, por exemplo, a sua opção em fazer com que os atores improvisassem ao máximo suas falas durante a filmagem, explorando a desenvoltura e característica de seus atores como se eles mesmos fossem os personagens, ao invés de simplesmente interpretarem um outro papel. Godard explorou o jeito zombeteiro de Belmondo no personagem Michel e o forte sotaque americano e erros de francês de Seberg ao interpretar Patricia, trazendo uma perspectiva romancista que revolucionou a escrita literária, através do monólogo interior e as frequentes gírias presentes nas falas dos personagens. A atuação de Melville como Parvulesco em Acossado reforça também essa síntese godardiana de pensadores que interpretam personagens em seus próprios papéis de pensadores. Ao mesmo tempo que Godard explorava ao máximo a característica particular de cada ator, ele colocava no discurso fílmico sua bagagem cultural, utilizando o cinema como seu próprio meio de expressão. Há por exemplo, ao longo do filme Acossado, diversas referências literárias como podemos observar, por exemplo, a longa cena em que Patricia e Michel estão conversando num quarto de hotel. A jovem pergunta a Michel se ele conhece o romance Palmeiras Selvagens de Faulkner e cita uma frase do livro: "entre a tristeza e o nada, prefiro a tristeza". Michel responde à frase de Faulkner dizendo: "a tristeza é idiotice, escolheria o nada, a tristeza é um compromisso". Pode-se observar como o discurso de Godard e o do personagem se cruzam, formando uma visão indireta e livre, promovendo um diálogo com a obra literária.

As personagens se expressam livremente no discurso-visão do autor, e o autor indiretamente, no das personagens. Em suma, é a reflexão nos gêneros, anônimos ou personificados, que constitui o romance, seu "plurilinguismo", seu discurso e visão. Godard dá ao cinema as potências próprias do romance. (DELEUZE, 1985, p. 225).

As colagens, citações, referências nos filmes de Godard vão ganhando sentido conforme são articuladas no desenvolvimento do filme e na ideia fílmica do autor. O fazer cinematográfico aproxima-se do ensaio.

A fotografia à luz natural de Raoul Coutard marca um grande diferencial no filme de Godard. A luz estourada na cena em que Michel está dando uma carona a Patricia faz com que a fotografia seja quase 
impressionista, como uma ilusão do natural, marcada por seguidos jump cuts (saltos) que alternam na nuca de Patricia, enquanto Michel faz uma descrição minuciosa dos detalhes anatômicos de Patricia. A sequência é mantida e, embora quebrada, é marcada pelos saltos, fazendo com que a cena ganhe uma materialização rítmica semelhante às pinceladas de uma pintura impressionista. Esses saltos marcam a construção da linguagem godardiana, acelerando abruptamente a cena e, ao mesmo tempo, sendo vistos sequencialmente, intensificando o poder visual da fotografia.

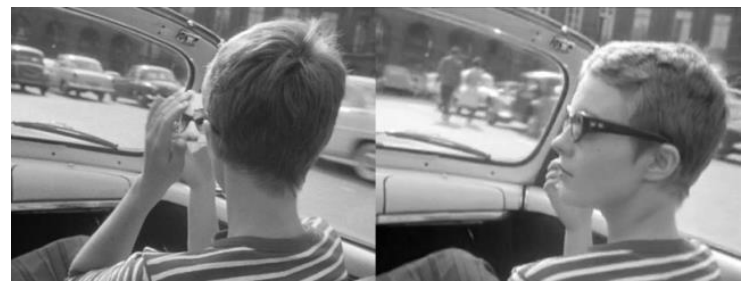

A sequência do hotel de Suède no filme Acossado concentra quase $1 / 3$ do filme, tendo duração de 24 minutos. A maior parte dos planos são filmados em plano sequência, com alguns jump cuts e falsos raccords (como a súbita mudança da blusa de listras horizontais de Patricia para uma blusa de listras verticais, causando uma descontinuidade da cena). Os planos sequencias do quarto no hotel de Suède são incrivelmente longos se comparados a qualquer filme da época ou anterior. Esses planos contínuos deixava o espectador muito mais próximo da relação afetiva que se desenvolvia entre os dois personagens, pois eram filmados em um ambiente interno e íntimo. Godard sedimentava, nessas longas sequências, a proximidade dos personagens que posteriormente iria separa-los. Os rostos dos atores/personagens são frequentemente aproximados na câmera. Enquanto Michel acaricia Patricia e comenta "eu queria saber o que existe por trás do seu rosto", a câmera se aproxima dos rostos, gestos e olhares que, ao desenrolar dos diálogos, tornam-se conflituosos. Patricia é frequentemente ignorada em seus assuntos por Michel que também é ignorado por Patricia, como se houvesse uma incomunicabilidade entre os sexos ao mesmo tempo em que o desejo está sempre presente. Em muitos planos, a fala do personagem não acompanha a imagem do mesmo, evidenciando uma disjunção entre som e imagem, também proposta por Godard em seu cinema.
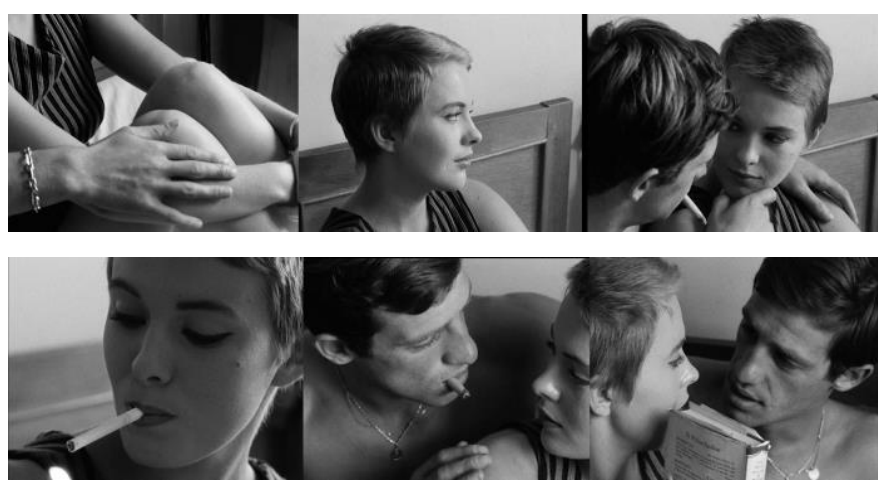

Patricia interroga Michel sobre a máxima do livro de Faulkner identificável na fotografia da cena, como também se refere ao pôster do pintor Renoir, 
perguntando a Michel se é tão bonita quanto a moça retratada. Frequentemente outras alusões a pinturas são evidenciadas pela câmera, sendo focadas com tanta força imagética quanto os retratos de Patricia e Michel, como são os pôsteres de quadros de Picasso que também enriquecem a bagagem cultural dos personagens, propondo diálogos com outras formas do fazer artístico. Fazer cinema não era diferente de pintar, de escrever, de pensar. O cinema moderno marca com Acossado uma transformação crítica da estética e une elementos entre texto e imagem sempre presentes no interstício das imagens, evidenciados pelos cortes, planos e movimento de câmera, que não teriam outra função senão a de escrever, pintar, pensar a imagem.

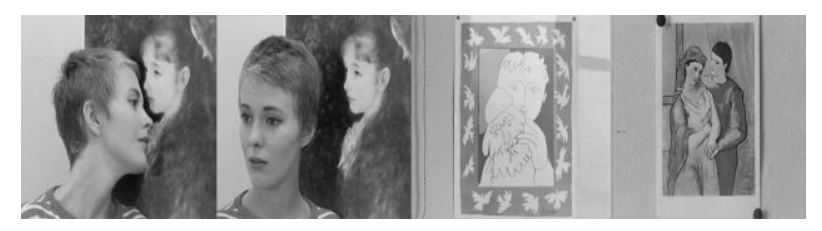

O poder dos closes dos rostos godardianos são como paisagens. Os retratos são tão abstratos que não configuram nenhuma análise psicológica, pois seu poder está na força imagética. Os atores de Godard serão sempre lembrados pelos seus rostos em seus filmes, imortalizados em um tempo específico, como se independente das imagens que passam, mudam e se transformam, fosse sempre mantida uma presença em cada frame. Na cena final, após a morte de Michel, Patricia retoma o costume de Michel de passar o polegar sobre a boca. A fala final da jovem repete uma frequente falta de vocabulário francês que aparece durante todo o filme: "quest que c'est 'dégueulasse'?"2. Por mais que não saiba o significado da palavra, a pergunta de conotação vocabular feita por Patricia é dirigida ao espectador, que ciente do significado, é questionado diretamente por uma pergunta que adquire conotação moral.

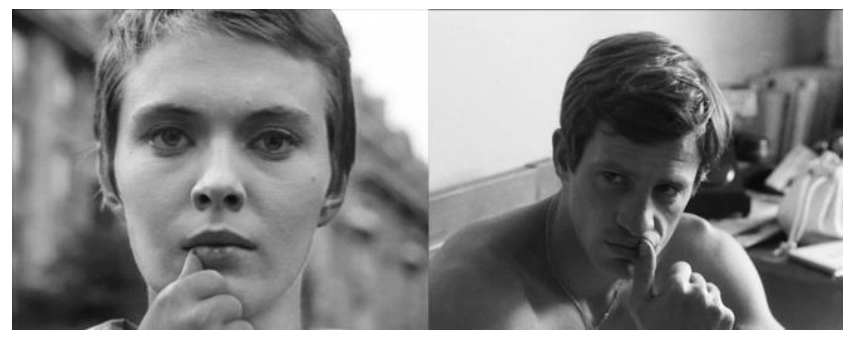

Godard promove em Acossado uma revolução constante da linguagem, utilizando-se de imagens que se transformam conforme o filme é construído e são compostas de espaços vazios entre imagens que se conectam para formar interstícios e imbricações com o pensamento crítico do autor e do espectador, que se permite uma análise crítica extra-fílmica. Os textos não são subordinados às imagens, os textos estão

\footnotetext{
${ }^{2}$ A frase "quest que c'est 'dégueulasse'?" pode ser traduzida por "o que é "nojenta"?".
} 
na composição das imagens em uma união entre cinema e pensamento.

BARTES, Roland. A Câmara Clara: Nota sobre a Fotografia/ Roland Bartes. Tradução: Júlio Castañon Guimarães - Rio de Janeiro: Nova Fronteira, 1984.

DELEUZE, Gilles, 1925-1995. A imagem-tempo. Tradução: Eloisa de Araujo Ribeiro; revisão filosófica Renato Janine Ribeiro. São Paulo: Brasiliense, 2013 - (Cinema 2)

MARIE, Michel. A Nouvelle Vague e Godard/Michel Marie. Tradução: Eloisa A. Ribeiro, Juliana Araújo Campinas, SP: Papirus, 2011. - (Coleção Campo Imagético)

MARIE, Michel; AUMONT, Jacques. A Análise do Filme. $3^{\text {a }}$ Edição, Armand Colin, 2004.

MASCARELLO, Fernando. História do cinema mundial. Tradução: Marcelo Felix $-7^{\mathrm{a}}$ ed. - Campinas, SP: Papirus, 2012. - (Coleção Campo Imagético)

Filmes Cinematográficos:

À BOUT DE SOUFLE (ACOSSADO). Jean-Luc Godard. França.
Produtor: Georges de Beauregard. 1959. Tempo de Projeção: 90 minutos. PRETO \& BRANCO. POLICIAL. Filme Cinematográfico.

\section{Revistas:}

L'Express, Situation du cinéma français" n. 71, maio de 1957.

L'Écran Français, n. 144, março de 1948.

\section{Internet:}

AUMONT, 2003. Dicionário Teórico e Crítico de Cinema. Disponível em:

https://gpesc.wordpress.com/2010/01/19/a umont-2003-\%E2\%80\%93-dicionarioteorico-e-critico-de-cinema/. Acesso em: 16 de agosto de 2016 às 11:00. 